\title{
Evaluation of Cranial Base Morphology of Pakistani Population in Skeletal Class I, II and III Malocclusions
}

\author{
Dr Faizan Ali,' Dr Rabia Aziz,, Dr Amna Malik, ${ }^{3}$ Hadiqa Afzal4 \\ 1-3FCPS II Trainee, 4Dental Technologist, \\ Orthodontic department of the Children Hospital \& Institute of Child Health Lahore, Pakistan \\ Correspondence: Dr Rabia Aziz; Email: rabiaumair83@gmail.com
}

\section{ABSTRACT}

Introduction: Cranial Base integrate different patterns of growth in various regions of the skull such as the nasal cavity, the oral cavity, and the pharynx. Anteroposterior jaw position is thought to be affected by cranial base growth. Although scientific literature shows conflicting results regarding both positive and negative correlation between the cranial base and skeletal malocclusions.

Materials \& Method: 138 patients selected according to the Inclusion criteria were divided into three major categories depending upon ANB angle. Class I, class II group and class III group. Pretreatment lateral cephalometric radiographs were taken. Linear and Angular measurements were measured. All the data was entered in SPSS version 25 and then analyzed by using descriptive statistics including mean, standard deviation and by using inferential statistics including Pearson correlation and ANOVA test.

Result: No significant differences were recorded between cranial base deflection angles (N-S-Ar and N-S-Ba) and malocclusions groups while Anterior cranial base length S-N was found to be maximum in class III and posterior cranial base length S-Ba was greater in class I.

Conclusion: Cranial base angles N-S-Ar and N-S-Ba did not demonstrate any statistically significant correlation with three malocclusion groups i.e. Class I, Class II and Class III and their correlation was negative.

Keywords: Cranial base, Cranial base angle, Malocclusions

\section{INTRODUCTION}

Malocclusion is a developmental deformity which may be of dental or skeletal origin. Malocclusions with skeletal discrepancies in the craniofacial region are caused by abnormal forms, sizes and positions of the cranial base, maxilla and mandible. The variation in the expression of different facial patterns is a result of interplay between various factors such as heredity, environment and function. These variable factors have an effect on the growth and development of the maxillofacial complex.

Cranial base plays an important role in growth of craniofacial region. It helps to integrate different patterns of growth in various regions of the skull such as the nasal cavity, the oral cavity, and the pharynx. As the maxilla is connected with the anterior part of the cranial base and the rotation of mandible is influenced by the maxilla, so a relationship can be found between cranial base morphology and the sagittal malposition of the jaws. Cranial base may affect the development of both cranium and the face as it is located on the junction between cranium, midface and glenoid fossa. ${ }^{2}$ Sella turcica lies near the Centre of the cranial base and divides it into anterior (Sella to Nasion) and posterior (Sella to Basion) limbs. The two limbs of the cranial base form a flexon of 130-145 degree at sella.,4

Although the cranial base largely develops in cartilage (chondrocranium), it shows both neural (from sella to foramen caecum) and somatic types of growth patterns. In the anterior segment, especially after early childhood, post natal growth is mainly due to enlargement of the frontal sinuses and surface remodeling in the nasion region. There is interstitial growth at the spheno-occipital synchondrosis (SOS), posteriorly. The maxilla shows attachment to the anterior segment and the mandible to the posterior segment. Just from this geometric relationship, it would be reasonable to assume that any change in flexion would alter maxillary and mandibular positions relative to the cranial base as well as to each other. ${ }^{5-7}$ Cranial base also plays a major role in defining various skeletal malocclusions. ${ }^{8}$

According to Moss 9 cranial base angle in subjects of class III malocclusion is smaller and other studies 
showed greater cranial base angle in Class II subject. ${ }^{10}$ According to Bhatia et al the cranial base angle (Ba$\mathrm{S}-\mathrm{N}$ ) was reduced and the legs (S-N) and (S-Ba) were shortened systematically from Class II, via Class I, to Class III malocclusions, although mandible exhibited no systemic difference between these three classes. ${ }^{11}$

Wil helm et al was also unable to confirm a link between cranial base angle and a class II pattern. ${ }^{12}$

In view of the conflicting evidence, a cephalometric study was conducted in our hospital to explore further the role of the cranial base angle in the various groups of malocclusion. The aim of this cross sectional study was to find out any possible relationship between cranial base angle and various horizontal skeletal dysplasia's in Pakistani population sample.

\section{MATERIALS AND METHOD}

Pretreatment lateral cephalometric radiographs of 138 patients seeking orthodontic treatment in Orthodontic department of The Children Hospital \& Institute of Child Health, from January 2019 to July 2019, were collected. All the lateral cephalometric radiographs were taken by single operator. Patients having no previous history of orthodontic treatment, no gross facial asymmetry, and age ranging between 12 to 17 years were included in this study. Radiographs were taken from the patient after filling of consent form at hospital.

Lateral cephalometric radiographs were traced upon an $\mathrm{A} 4$ size acetate paper 33 with $2 \mathrm{~B}$ or $3 \mathrm{HB}$ hard lead pencil over well-illuminated viewing screen. The linear measurement was recorded with a measuring scale up to precision of $0.5 \mathrm{~mm}$. The angular measurements were analyzed with a protractor up to a precision of $0.5 \mathrm{~mm}$

These measurements were counter checked by coauthor in order to eliminate intra- observer bias.

All the patients were divided into three major categories depending upon ANB angle and dental occlusion.

Group I: Skeletal Class I patients having ANB $1^{\circ}-4^{\circ}$

Group II: Skeletal Class II patients having ANB $>4^{\circ}$

Group III: Skeletal Class III patients having ANB $<0^{\circ}$

Following landmarks were used in this study (Fig 1)

POINT A traced as the deepest innermost point on the contour of the premaxilla

POINT B traced as the innermost point on the contour of the mandible

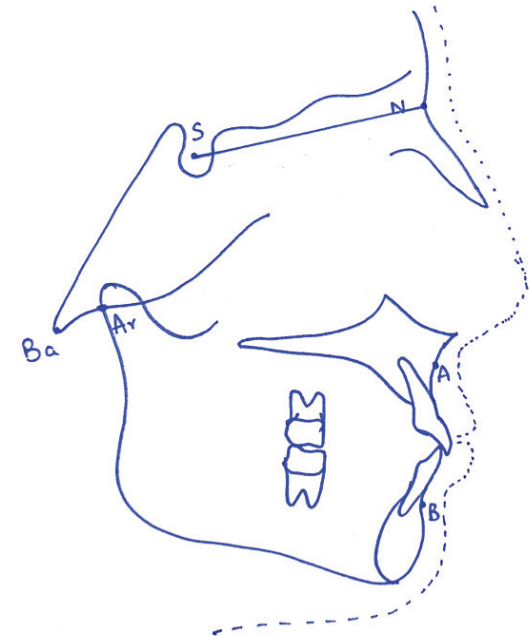

Figure 1: Landmarks used in the study

SNA: Angle formed between NA and SN plane. Norm is $80^{\circ}-82^{\circ}$

SNB: Angle formed between NB line and SN plane. Norm is $78^{\circ}-82^{\circ}$

ANB ANGLE: Angle formed by the intersection of lines from points $A$ and $B$ to nasion. (SNA angle minus SNB angle)

ARTICULARE (Ar) (the point at the junction of inferior border of posterior cranial base (occipital bone) and posterior border of ramus)

BASION (Ba) (lower most point on the anterior rim of foramen magnum)

NASION (N): The anterior point of the intersection between the frontal and nasion bones.

SELLA(S) (geometric centre of pitutary fossa)

SN PLANE: Horizontal plane joining points Sella and Nasion

Angles measured were SNA SNB and ANB for skeletal horizontal dysplasias. Cranial base angulations measured were, NSBa and NSAr.

All the data were subjected to computerized statistical analysis by using descriptive statistics including mean, standard deviation, standard error, minimum and maximum and by using inferential statistics including ANOVA test and Pearson correlation test in SPSS (Statistical Packages for Social Sciences) version 25.

All the data of the sample were subjected to computerized statistical analysis using SPSS (Statistical Packages for Social Sciences) version 21. Quantitative variables were written as Meantstandard deviation. One way analysis (ANOVA) was used for comparison of quantitative parameters among groups. 
Table 1: Descriptive statistics according to three groups

\begin{tabular}{|c|c|c|c|}
\hline & N & MEAN & STANDARD DEVIATION \\
\hline S-N-Ba & 138 & & $5.66^{\circ}$ \\
\hline CLASS I & 44 & $127.90^{\circ}$ & $4.71^{\circ}$ \\
\hline CLASS II & 68 & $128.86^{\circ}$ & $5.65^{\circ}$ \\
\hline CLASS III & 26 & $129.38^{\circ}$ & \\
\hline S-N-Ar & 138 & & $7.27^{\circ}$ \\
\hline CLASS I & 44 & $121.46^{\circ}$ & $5.51^{\circ}$ \\
\hline CLASS II & 68 & $122.46^{\circ}$ & $5.74^{\circ}$ \\
\hline
\end{tabular}

Table 2: Anova applied for measurements.

\begin{tabular}{|c|c|c|c|c|c|}
\hline Group & Sum of Squares & Degree of freedom & Mean Square & Variance ratio(F) & P-value \\
\hline N-S-Ar & 117.495 & 2 & 58.747 & 1.547 & 0.217 \\
\hline N-S-Ba & 54.519 & 2 & 27.260 & 1.007 & 0.368 \\
\hline SNA & 957.775 & 2 & 478.887 & 8.709 & 0.000 \\
\hline SNB & 175.614 & 2 & 87.807 & 1.556 & 0.215 \\
\hline ANB & 1848.033 & 2 & 2924.016 & 254.729 & 0.000 \\
\hline N-S & 61.780 & 2 & 30.890 & 1.626 & 0.201 \\
\hline S-Ba & 67.503 & 2 & 33.751 & 2.632 & 0.076 \\
\hline
\end{tabular}

Table 3: Correlation coefficient with pooled group data

\begin{tabular}{|c|c|c|c|c|c|c|c|}
\hline & N-S-Ar & N-S-Ba & N-S & S-Ba & SNA & SNB & ANB \\
\hline SNA & -0.079 & -0.031 & 0.057 & 0.080 & ----- & 0.856 & 0.331 \\
\hline SNB & -0.055 & -0.034 & 0.017 & 0.164 & 0.856 & $---{ }^{--}$ & $0-.205$ \\
\hline ANB & -0.048 & 0.004 & -0.140 & -0.148 & 0.331 & -0.205 & ----- \\
\hline S-Ba & 67.503 & 2 & 33.751 & & 2.632 & & 0.076 \\
\hline
\end{tabular}

\section{RESULT}

In this study, 138 (57 males and 81 females) lateral cephalograms of patients seeking orthodontic treatment were analyzed. All of the sample were Pakistanis with an age ranged between 12-17 years. Distribution according to malocclusion were $49 \%$ Class II subjects, $32 \%$ class I subjects and $19 \%$ class III subjects. Mean cranial base angle with basion point was found to be $128.71^{\circ}+5.34^{\circ}$ while with articulare was found to be $122.62^{\circ}+6.17^{\circ}$. Mean N-S-Ba for class I was $127.90^{\circ}$ +5.66 with maximum of $144^{\circ}$ and minimum of $119^{\circ}$. As for class II average N-S- Ba was found to be $128.86^{\circ}$ $+4.71^{\circ}$ with maximum of $142^{\circ}$ and minimum of $119^{\circ}$. For class III average N-S-Ba was $129.38^{\circ}+5.65^{\circ}$ with maximum of $140^{\circ}$ and minimum of $119^{\circ}$. As for N-S-Ar, it was calculated to be average of $123.96^{\circ}+5.74^{\circ}$, $122.46^{\circ}+5.51^{\circ}$ and $121.46^{\circ}+7.27^{\circ}$ for class III, II and I respectively. (Table 1 )

One way analysis ANOVA was applied to the three groups of malocclusion in the study sample to compare their means. The $\mathrm{p}$ value was 0.217 for $\mathrm{N}-\mathrm{S}-\mathrm{Ar}$ and was 0.368 for N-S Ba which is statistically insignificant. (Table 2)

Little correlation was evident between angle ANB and cranial base parameters when looking at pooled or individual group data (Tables 3). This suggests that there is no direct relationship between the cranial base and class of malocclusion.

\section{DISCUSSION}

The aim of our study was to find out if any relationship exists between cranial base angles and horizontal skeletal dysplasias. The results of this study showed that the cranial base angles are greater in class III than Class II which in turn greater than class I showing insignificant correlation between Horizontal skeletal dysplasis and cranial base angles. This result is in agreement with various studies. ${ }^{12,13}$

The cranial base angle at birth is approximately 142, but then reduces to 130 at 5 years of age. From 5 to 15 years the cranial base angle is relatively stable. ${ }^{14}$ Morphology of basicranium, head neck posture, soft tissue stretching and breathing pattern effects skeletal malocclusions. 
The anatomically temporomandibular joint is positioned away from mid sagittal plane. This leads to the fact that that variation in cranial base growth might not get translated to the mandible. As most of the cephalometric analyses are based on medial sagittal plane changes in mandibular position due to changes in cranial base might not be observed. The observations in the present study support this assumption and are in agreement with studies reported by other authors. ${ }^{15,16}$ Jarvinen ${ }^{17}$ reported a larger SNAr angle in class II subjects. This also suggests that there is no direct relationship between the cranial base and class of malocclusion.

The results of our study conflicted with other studies ${ }^{18,19}$ which showed that the cranial base angle was found larger in the order of class II > class I > class III.

Finally it should be noted that the differences between the results of this study and the other studies may be attributed to the differences in the case selection procedure. Another fact to consider is that for example $\mathrm{N}$-S-Ar angle can vary due to changes in the height of the anterior cranial base..$^{20}$

\section{CONCLUSION}

From this study it is concluded that:

- The cranial base angle does not appear to play an important role in the establishment of malocclusion.

- Cranial base angles S-N-Ar and S-N-Ba did not demonstrate any statistically significant correlation with Class I, II and III malocclusions.

\section{REFERENCES}

1. Kuroe K, Rosas A, Molleson T. Variation in the cranial base orientation and facial skeleton in dry skulls sampled from three major populations. Eur J Orthod 2004;26(2):201-7.

2. Scott JH. The cranial base. Am J Phys Anthropol 1958; 16(3): 319-348

3. E Sanggarnjanavanich S, Sekiya T, Nomura Y, Nakayama T, Hanada N, Nakamura Y. Cranial base morphology in adults with skeletal class III malocclusion. American J Orthod and Dentofacial Orthop.2014 Jul 1; 146(1):82-91.

4. Wu XP, Xuan J, Liu HY, Hue MR, Bing L. Morphological char-acteristics of the cranial base of early Angle's Class II Division 1 Malocclusion in Permanent Teeth.Int. J. Morphol.2017 june 1; 35(2).

5. Gong A,Li J,Wang Z, Li Y, Hu F, Li Q, Miao D, Wang L. Cranial base characteristics in anteroposterior malocclusions: A meta-analysis. The Angle Orthod. 2015 Nov 3:86(4):668-80

6. Almeida KC, Raveli TB, Viera Cl, Santos-Pinto AD, Raveli DB. Influence of the cranial base flexion on Class I, II and III malocclusions: a systemic review. Dental Press J Orthod. 2017 Sept- Oct;22(5):56-66.

7. Awad AM, Gaballah SM, Gomaa NE. Relationship between cranial base and jaw base in different skeletal patterns. Orthodontic Waves.2018 June 1;77(2);125-33

8. Cossio L, Lopez J Rueda ZV, Botero-MariacaP. Morphological configuration of the cranial base among children aged 8 to 12 years.BMC Research notes. 2016 Dec 9:(1):30.

9. Moss ML, Greenberg SN. Postnatal growth of the human skull base. Angle Orthod 1955 Apr;25(2):77-84

10. Bhattacharya A, Bhatia A, Patel D, Mehta N, Parekh H, Trivedi R. Evaluation of relationship between cranial base angle and maxillofacial morphology in Indian population: A cephalometric study. J Orthod Sci 2014; 3(3): 74-80.

11. Bhatia SN, Leighton BC. A manual of facial growth. Oxford: Oxford University Press; 1993.

12. Wilhelm BM, Beck FM, Lidral AC, Vig KW. A comparison of cranial base growth in class I and class II skeletal patterns. Am J Orthod Dentofac Orthop. 2001;119:401-405.

13. Polat OO, Kaya B. Changes in cranial base morphology in different malocclusions. Orthod Craniofac Res 2007; 10(4):216-21.

14. Kerr WJS. A method of superimposing serial lateral cephalometric films for the purpose of comparison: a preliminary report. Br J Orthod. 1978;5:51-53.

15. Battagel JM. The aetiology of class III malocclusion examined by tensor analysis. Br J Orthod. 1993;20:283-296.

16. Guyer EC, Ellis EE, McNamara JA, Behrents RG. Components of class III malocclusion in juveniles and adolescents. Angle Orthod. 1986;56:7-30.

17. Ishii N, Deguchi T, Hunt NP. Morphological differences in the craniofacial structure between Japanese and Caucasian girls with Class II division 1 malocclusion. Eur J Orthod. 2002 Feb;24(1):61-7.

18. Fatehulla KS. The relationship between cranial base angle and malocclusion among Kurdish adults in Sulaimania city: A lateral cephalometric study. College of Dentistry, University of Sulaimania, 2009.

19. Mossa AA. Orientation of the cranial base on facial skeleton in different skeletal classes of Iragi adults. A master thesis, Orthodontic department, Baghdad University, 2007.

20. Andria LM, Leite LP, Prevatte TM, King LB. Correlation of the cranial base angle and its components with other dental / skeletal variables and treatment time. Angle Orthod 2004: 74(30): 361-66. 